\title{
Analisa Kebutuhan Pelayanan Trans Padang Koridor Pusat Kota - Pusat Pemerintah
}

\author{
Wiwin Putri Zayu \\ Universitas Dharma Andalas Padang \\ winzayu@gmail.com
}

\begin{abstract}
Increasing the need of mass transportation in Padang city is needed to overcoming the chaos of transportation. For that to be done the analyst service needs for Trans Padang corridor Center of City-center government.a From result of research known that corridor Trans Padang for developmentof trajectory Trans Padang corridor Center of City-Center Government are Imam Bonjol street - Karya - Gereja - Diponegoro - Hangtuah - Samudera - S. Parman - Khatib Sulaiman - Jhon Anwar - Gadjah Mada - Siteba - Simp. Balai Baru - Sungai Sapih - Aie Pacah for direction go and go home rute Aie Pacah - Sungai Sapih - Simp. Balai Baru - Siteba - Gadjah Mada - Jhoni Anwar - S. Parman - Juanda - Veteran - Damar - Pemuda - Diponegoro - Gereja - Pondok - M. Thamrin - Imam Bonjol - Hasanuddin - Bagindo Aziz Chan - M. Yamin - Imam Bonjol. Bassed on potential demand of Trans Padang passenger corridor Center of City-Center Government of all modes is 24.783 passenger with the price around Rp. 3500,- to Rp. 4000,-. Based on land analysis the number of shelters needed to corridor Center of City-Center Government is 39 shelters for direction go n 39 shelters for direction go home with the long of trajection about 22,94 km. And bus that can operate on this corridor is a medium size, because there is one narrow road segment that cannot be passed by big bus.

Peningkatan kebutuhan pelayanan angkutan masal dikota padang untuk mengatasi kesemrawutan transportasi sangat dibutuhkan, untuk itu dilakukan analisa kebutuhan pelayanan Trans Padang koridor Pusat Kota - Pusat Pemerintahan. Dari hasil penelitian diketahui bahwa koridor Trans Padang untuk pengembangan lintasan Trans Padang Pusat kota - Pusat Pemerintahan adalah jalan Imam Bonjol - Karya - Gereja - Diponegoro - Hangtuah - Samudera - S. Parman - Khatib Sulaiman - Jhon Anwar - Gadjah Mada - Siteba - Simp. Balai Baru - Sungai Sapih - Aie Pacah untuk arah pergi dan arah pulang dengan rute Aie Pacah - Sungai Sapih - Simp. Balai Baru - Siteba - Gadjah Mada - Jhoni Anwar - S. Parman - Juanda - Veteran - Damar - Pemuda - Diponegoro Gereja - Pondok - M. Thamrin - Imam Bonjol - Hasanuddin - Bagindo Aziz Chan - M. Yamin - Imam Bonjol. Berdasarkan Potensi potensial demand penumpang Trans Padang koridor Pusat Kota-Pusat Pemerintahan dari seluruh moda adalah 24.783 penumpang dengan kisaran ongkos sekitar Rp. 3500 - Rp. 4000. Berdasarkan analisis tata guna lahan maka jumlah halte yang dibutuhkan Trans Padang untuk koridor Pusat Kota-Pusat Pemerintahan adalah 39 halte untuk arah pergi dan 39 halte untuk arah pulang dengan panjang trayek $22,94 \mathrm{~km}$, sedangkan bus yang bisa beroperasi pada koridor ini adalah bus ukuran sedang karena ada salah satu ruas jalan yang sempit sehingga tidak bisa dilalui oleh bus ukuran besar.
\end{abstract}

Kata Kunci : Analisa Kebutuhan, Trans Padang, Koridor Pusat Kota - Pusat Pemerintahan

\section{Pendahuluan}

Perubahan tata guna lahan seperti perpindahan pusat pemerintahan ke daerah Aia Pacah menimbulkan peningkatan tarikan perjalanan pada trayek Pusat Kota - Pusat Pemerintahan yang menimbulkan peningkatan kebutuhan moda transportasi. Moda transportasi yang didominasi oleh kendaraan kecil (angkot) menyebabkan permasalahan dalam transportasi seperti kemacetan yang mengakibatkan berkurangnya kenyamanan masyarakat dalam berkendaraan. Karena adanya permasalahan dalam transportasi maka dilakukan penelitian untuk mengkaji kebutuhan masyarakat akan alat transportasi massal demi mengurangi permasalahan dalam transportasi terutama kemacetan lalu lintas pada koridor Pusat Kota-Pusat Pemerintahan.

Pada tahun 2014 telah dilaksanakan pengoperasian koridor I Trans Padang (Pusat Kota - Lubuk Buaya) dengan menggunakan 
pihak ketiga dalam pengoperasiannya dengan sistem buy the service (pembelian jasa layanan) dimana pihak ketiga mengikat kontrak dengan pemerintah dan pembayaran dilakukan melalui produksi kilometer.

Berdasarkan keluaran Dokumen Rencana Induk Transportasi Kota Padang 2010 - 2030, pelayanan Trans Padang direncanakan 5 (lima) koridor yang melayani jalan - jalan utama di Kota Padang, untuk itu sudah seharusnya dilaksanakan pengembangan mengingat pelayanan Angkutan Massal (Trans Padang) merupakan kebijakan Pemerintah dan yang perlu didorong untuk terciptanya pelayanan angkutan umum yang efisien dan sustainable. Dari lima koridor yang tertulis pada Dokumen Rencana Induk Transportasi Kota Padang 2010 - 2030 maka diambil penelitian pada koridor Pusat Kota Pusat Pemerintahan dengan lingkup pekerjaan : Menghitung demand Trans Padang koridor Pusat Kota - Pusat Pemerintahan, penentuan kebutuhan dan lokasi halte.

\section{Metodologi penelitian}

Data yang dibutuhkan pada penelitian ini adalah data primer dan data sekunder. Data primer diperoleh dengan melakukan survey lalu lintas berupa kebutuhan (demand) angkutan umum pada koridor Pusat KotaPusat Pemerintahan dan perhitungan bangkitan perjalanan. Survey lalu lintas dilakukan dalam bentuk survey on bus/survey dinamis yaitu melakukan wawancara dan penyebaran kuisioner kepada responden diatas kendaraan umum, yaitu kendaraan umum/angkot menuju siteba (angkot biru), dan angkot dari jalan S. Parman-Imam Bonjol. Kemudian data diolah dengan metoda revealed preference. Pengumpulan data sekunder yaitu dengan melakukan studi literatur. Data sekunder pada penelitian ini adalah data penduduk kota Padang yang dibagi dalam beberapa zona yang masingmasing mempunyai karakteristik tersendiri. Zona di dalam daerah kajian disebut zona internal dan zona di luar daerah kajian disebut zona eksternal. Basis dari sistem zona yang digunakan dalam pemodelan transportasi ini adalah wilayah kelurahan yang dikelompokkan menjadi 36 zona untuk zona internal dan 3 zona eksternal dari arah Padang Pariaman, Solok dan Pesisir Selatan. Sistem zona dengan basis kelurahan dipilih ini karena ketersediaan data terutama data perjalanan orang (O-D)

Analisis data pada penelitian ini dilakukan dengan beberapa cara yaitu:

a. Analisis potensi demand yaitu analisis yang dilakukan untuk mengetahui kebutuhan penumpang akan angkutan umum masal seperti Trans Padang.

b. Analisis bangkitan-tarikan dilakukan untuk mengkaji kelayakan adanya bus Trans Padang untuk jurusan Pusat Kota-Pusat Pemerintahan.

c. Analisis tata guna lahan untuk menentukan jumlah halte dan kebutuhan halte di suatu tempat

d. Analisis geometrik jalan dilakukan untuk menentukan penempatan halte bus Trans Padang dan menentukan jenis bus yang akan digunakan.

\section{Hasil dan pembahasan}

Tujuan dilakukannya analisis terhadap pemilihan moda ini adalah untuk mengetahui seberapa besar permintaan masyarakat akan moda angkutan yang dibutuhkan dalam melayani kegiatan masyarakat. Beberapa faktor yang mempengaruhi pemilihan moda dapat dibagi dalam tiga kategori, yaitu: 
a. Karakteristik perjalanan, meliputi :

- Panjang perjalanan, mencakup : Jarak atau panjangnya rute yang ditempuh, waktu yang dihabiskan dalam menempuh perjalanan, waktu yang ditempuh moda lain.

- Tujuan dari perjalanan yang dilakukan.

b. Karakteristik si pembuat perjalanan yang meliputi : Pendapatan, pemilikan kendaraan, kepadatan dan tata guna lahan, faktor sosio ekonomi lainnya seperti ukuran keluarga, umur, jenis kelamin, dan sebagainya.

c. Karakteristik sistem transportasi yang terdiri dari : Waktu perjalanan, biaya perjalanan, tingkat pelayanan, aksesibilitas.

\section{Koridor Pusat Kota - Pusat Pemerintahan}

Koridor Pusat Kota - Pusat

Pemerintahan adalah koridor yang melayani wilayah Barat menuju wilayah Timur Kota Padang atau sebaliknya. Dari segi tataguna lahan koridor Pusat Kota - Aia Pacah lintasan rute terdiri dari Kawasan pemukiman yang mendominasi, kawasan perkantoran, kawasan pendidikan serta kawasan perdagangan. Pada koridor ini kondisi pelayanan angkutan umumnya masih belum optimal, dimana sebagian besar masyarakat masih banyak yang mengandalkan kendaraan pribadi. Kawasan pada koridor ini sebagian besar masih dalam tahap perkembangan khususnya kawasan by pass. Sehingga kedepannya perlu peningkatan pelayanan angkutan umum massal. Selain itu, dengan adanya peningkatan pelayanan angkutan umum massal diharapkan dapat mengurangi komposisi kendaraan yang ada dijalan sehingga dapat mengurangi dampak kemacetan Ialu lintas.

Pola perjalanan kendaraan pribadi untuk Koridor Pusat Kota - Pusat Pemerintahan (Aia Pacah) terdiri dari 10 zona, antara lain: Pusat Kota (1), Padang Selatan (2), Purus (3), Padang Baru (8), Ulak Karang (14), Lapai (15), Siteba (16), Korong Gadang (17), Kurao Pagang (23), Aia Pacah (28). Total bangkitan untuk pola perjalanan kendaraan pribadi pada koridor Pusat Kota - Pusat Pemerintahan (Aia Pacah) adalah sebesar 77.829 perjalanan, sedangkan untuk total tarikannya adalah sebesar 96.491 perjalanan. Total bangkitan untuk pola perjalanan angkutan umum pada koridor Pusat Kota Pusat Pemerintahan (Aia Pacah) adalah sebesar 262.847 perjalanan, sedangkan untuk total tarikannya adalah sebesar 304.887 perjalanan.

Dari penelitian diperoleh distribusi masing-masing zona yang berada pada lintasan Koridor Pusat Kota - Pusat Pemerintahan umumnya mendistribusikan perjalanan ke zona 1, ada beberapa zona yang distribusi tertinggi diluar zona 1 (CBD) seperti zona 8,14, 15, 17, 23, 28. Masingmasing zona tersebut memiliki distribusi zona yang berbeda satu dengan yang lain. Bangkitan tarikan perjalanan kendaraan pribadi untuk koridor Pusat Kota - Pusat pemerintahan didominasi oleh zona 14 (Ulak Karang). Nilai bangkitan perjalanan adalah sebesar 13.678 perjalanan sedangkan untuk nilai tarikan perjalanannya adalah sebesar 23.844 perjalanan. Pada zona 2 (kel. Berok, Ranah Parak Rumbio, Pasa Gadang dan Pondok) perjalanan terdistribusi ke zona 1, 13 dan 4. Kemudian zona 3 yang merupakan zona yang dilintasi koridor Pusat Kota - Pusat 
Pemerintahan banyak terdistribusi ke zona 1 (CBD), 29 dan zona 8, sedangkan zona 8 yang juga terdapat lintasan utama banyak terdistribusi pada zona 3,14 dan 9. Selanjutnya zona 14 distribusi tertinggi terdapat pada zona 23, 1 dan 17, Kemudian zona 15 distribusi tertinggi banyak terdapat pada zona 17,1 dan 3. Zona 16, banyak terdistribusi ke zona 1,8,10. Kemudian zona 17 yang merupakan zona yang dilintasi koridor utama banyak mendistribusikan perjalanan ke zona 15,14 , 4 . Zona 23 , banyak terdistribusi ke zona 16, 32 dan 8. Dan zona 28 yang merupakan zona yang dilewati koridor Pusat Kota - Pusat Pemerintahan banyak terdistribusi ke zona 37, 32, 29. Rincian daerah distribusi masing masing zona dapat dilihat pada tabel dibawah ini :

Tabel 3.1 Daerah distribusi zona yang dilintasi Koridor Pusat Kota - Pusat Pemerintah

\begin{tabular}{|c|c|c|c|c|c|c|}
\hline Zona & & & & Distribusi zona & & \\
\hline 2 & 1 & Kel. Olo & 13 & Kel. Parak Gadang & 4 & Jati \\
\hline & & Kel. Kampung Jawa & & Kel. Simp. Haru & & Jati Baru \\
\hline & & Kel. Belakang Tangsi & & Kel. Marapalam & & \\
\hline & & Kel. Belakang Pondok & & & & \\
\hline 3 & 1 & Kel. Olo & 29 & Kel. Batang Kabung & 8 & Kel. Flamboyan Baru \\
\hline & & Kel. Kampung Jawa & & Kel. Bungo Pasang & & Kel. Rimbo Kaluang \\
\hline & & Kel. Belakang Tangsi & & Kel. Pasie Nan Tigo & & Kel. Lolong Belanti \\
\hline & & Kel. Belakang Pondok & & Kel. Batang Kabung & & Kel. Flamboyan Baru \\
\hline 8 & 3 & Kel. Ujung Gurun & 14 & Kel. Ulak Karang Utara & 9 & Kel. Tb. Gadang \\
\hline & & Kel. Purus & & Kel. Ulak Karang Selatan & & Kel. Gn. Panggilan \\
\hline & & Kel. Padang Pasir & & & & \\
\hline 14 & 23 & Kel. Korao Pagang & 1 & Kel. Olo & 17 & Kel. Kalumbuk \\
\hline & & Kel. Sei, Sapih & & Kel. Kampung Jaya & & Kel. Korong Gadang \\
\hline & & & & Kel. Belakang Tangsi & & \\
\hline & & & & Kel. Belakang Pondok & & \\
\hline 15 & 17 & Kel. Kalumbuk & 1 & Kel. Olo & 3 & Kel. Ujung Gurun \\
\hline & & Kel. Korong Gadang & & Kel. Kampung Jaya & & Kel. Purus \\
\hline & & & & Kel. Belakang Tangsi & & \\
\hline & & & & Kel. Belakang Pondok & & \\
\hline 16 & 1 & Kel. Olo & 8 & Kel. Flamboyan Baru & 10 & Kel. Alai Parak Kopi \\
\hline & & Kel. Kampung Jaya & & Kel. Rimbo Kaluang & & Kel. Ampang \\
\hline & & Kel. Belakang Tangsi & & Kel. Lolong Belanti & & \\
\hline & & Kel. Belakang Pondok & & Kel. Flamboyan Baru & & \\
\hline 17 & 15 & Kel. Kampung Olo & 14 & Kel. Ulang Karang Utara & 4 & Jati \\
\hline & & Kel. Kampung Lapai & & Kel. Ulak Karang Selatan & & Jati Baru \\
\hline 23 & 16 & Kel. Surau Gadang & 32 & Kel. Lubuk Mintrun & 8 & Kel. Flamboyan Baru \\
\hline & & Kel. Gurun Lawas & & Kel. Gunung Sarik & & Kel. Rimbo Kaluang \\
\hline & & & & & & Kel. Lolong Belanti \\
\hline & & & & & & Kel. Flamboyan Baru \\
\hline 28 & 37 & $\begin{array}{l}\text { Bukittinggi, Par dan } \\
\text { sekitarnya }\end{array}$ & 32 & Kel. Lubuk Mintrun & 29 & \\
\hline & & & & Kel. Gunung Sarik & & \\
\hline
\end{tabular}

Sumber:Hasil Analisis, 2016

\section{Bangkitan dan Tarikan Angkutan Umum}

Dari penelitian diperoleh distribusi perjalanan juga banyak mengarah ke zona 1 (satu) yakni zona CBD dan zona 23 (Kurao
Pagang, Sungai Sapih) dimana zona tersebut merupakan pusat rumah sakit pemerintah daerah Kota Padang, disamping zona 23 juga zona yang banyak pemukiman. 
Nilai bangkitan tarikan perjalanan angkutan umum pada koridor Pusat Kota Pusat Pemerintahan didominasi oleh zona 23 (Kurao Pagang). Nilai bangkitan perjalanan untuk zona 23 (Kurau Pagang) adalah sebesar 28.107 perjalanan sedangkan untuk tarikan perjalannnya adalah sebesar 23.625 perjalanan.

\section{Rencana Koridor Lintasan Trans Padang}

Koridor Lintasan Pusat Kota - Pusat Pemerintahan merupakan koridor untuk mendukung aksesibilitas Ibu Kota dari Kota Padang. Koridor lintasan Pusat Kota - Pusat Pemerintahan yang dilalui Trans Padang beririsan dengan trayek eksisting. Trayek yang beririsan dengan Trans Padang merupakan demand potensial yang akan beralih ke Bus Trans Padang. Dari matrik asal tujuan kendaraan pribadi maupun angkutan umum atau kecendrungan masyarakat untuk mobilisasi asal dan tujuan maka lintasan potensial dari sisi demand untuk dikembangkan adalah sebagai berikut :

Tabel 3.2 Rekomendasi Koridor Lintasan Pusat Kota - Pusat Pemerintahan

\begin{tabular}{|c|c|c|c|c|}
\hline No & Koridor & Jurusan & & Lintasan \\
\hline \multirow[t]{2}{*}{1} & \multirow[t]{2}{*}{ III } & \multirow[t]{2}{*}{$\begin{array}{l}\text { Pusat Kota - } \\
\text { Pusat } \\
\text { Pemerintahan }\end{array}$} & Pergi & $\begin{array}{l}\text { Imam Bonjol - Karya - Gereja - Diponegoro - } \\
\text { Hangtuah - Samudera - S. Parman - Khatib } \\
\text { Sulaiman - Jhon Anwar - Gadjah Mada - Siteba - } \\
\text { Simp. Balai Baru - Sungai Sapih - Aie Pacah }\end{array}$ \\
\hline & & & Pulang & $\begin{array}{l}\text { Aie Pacah - Sungai Sapih - Simp. Balai Baru - } \\
\text { Siteba - Gadjah Mada - Jhoni Anwar - S. Parman } \\
\text { - Juanda - Veteran - Damar - Pemuda - } \\
\text { Diponegoro - Gereja - Pondok - M. Thamrin - } \\
\text { Imam Bonjol - Hasanuddin - Bagindo Aziz Chan - } \\
\text { M. Yamin - Imam Bonjol }\end{array}$ \\
\hline
\end{tabular}

Sumber:Hasil Analisis, 2016

\section{Potensial Demand}

Koridor Lintasan Pusat Kota - Pusat Pemerintahan memiliki irisan yang cukup banyak dengan trayek eksisting yaitu sebanyak 825 unit kendaraan, sedangkan trip perjalanan adalah sebanyak kendaraan yang beroperasi sebanyak 6.668 trip angkutan umum. Kemudian demand potensial yang diperoleh dari survei naik turun penumpang pada trayek yang beririsan dengan koridor lintasan Trans Padang Pusat Kota - Pusat Pemerintahan. Berdasarkan penelitian diperoleh jumlah demand potensial yang ada pada lintasan Pusat Kota - Pusat Pemerintahaan adalah sebanyak 18.084 penumpang. Namun demand ini bukanlah demand real yang ingin naik ke Angkutan
Trans Padang. Demand real Trans Padang harus dilihat dari keinginan penumpang angkutan kota untuk berpindah ke Trans Padang

\section{Potensial Demand On Board}

Berdasarkan hasil survey on board Potensial demand mode shift MPU (Mobil Penumpang Umum) ke Trans Padang pada koridor Pusat kota-Pusat Pemerintahan cenderung lebih sensitif terhadap harga tiket. Dengan harga tiket Rp.3500, estimasi demand Trans Padang adalah $77.5 \%$ dari demand MPU eksisting. Namun persentasenya mengalami penurunan hingga menjadi kurang dari $50 \%$ apabila harga tiket dinaikan menjadi Rp.5000 dan cenderung stabil jika harganya dinaikkan lagi. 
Tabel 3.3 Mode shift MPU- Trans Padang koridor Pusat Kota-Pusat Pemerintahan

\begin{tabular}{|c|c|c|c|c|}
\hline & \multirow[t]{2}{*}{ Skenario } & \multicolumn{2}{|c|}{$\begin{array}{c}\text { Jumlah responden berdasarkan } \\
\text { moda pilihan (Orang) }\end{array}$} & \multirow{2}{*}{$\begin{array}{l}\text { Mode } \\
\text { shift (\%) }\end{array}$} \\
\hline & & Trans Padang & MPU & \\
\hline 1 & 2500 (Umum)/1500 (Pelajar) & 179 & 21 & 89.5 \\
\hline 2 & 3000 (Umum)/1500 (Pelajar) & 173 & 27 & 86.5 \\
\hline 3 & 3500 (Umum)/1500 (Pelajar) & 155 & 45 & 77.5 \\
\hline 4 & 4000 (Umum)/1500 (Pelajar) & 140 & 60 & 70.0 \\
\hline 5 & 4500 (Umum)/1500 (Pelajar) & 103 & 97 & 51.5 \\
\hline 6 & 5000 (Umum)/1500 (Pelajar) & 91 & 109 & 45.5 \\
\hline 7 & 5500 (Umum)/1500 (Pelajar) & 86 & 114 & 43.0 \\
\hline 8 & 6000 (Umum)/1500 (Pelajar) & 86 & 114 & 43.0 \\
\hline 9 & 6500 (Umum)/1500 (Pelajar) & 86 & 114 & 43.0 \\
\hline
\end{tabular}

Sumber: Hasil Survey diolah, 2016

\section{WTP dan ATP gabungan (on board)}

Kecenderungan penumpang beralih karena karaktersitik bus dan layanannya dengan tarif tertentu disebut dengan Willingness To Pay (WTP) sedangkan kemampuan responden untuk membayar biaya menggunakan angkutan umum berdasarkan pendapatannya disebut dengan Ability To Pay. Boleh jadi WTP penumpang melebihi ATP atau sebaliknya. Disamping itu, WTP dan ATP bisa juga berhimpit/beririsan.

Untuk koridor Pusat kota, WTP dan ATP nya dapat di lihat pada Gambar 3.1 Terlihat bahwa grafik WTP berada disebelah kanan dari grafik ATP yang mengindikasikan WTPnya lebih tinggi dibandingkan ATPnya. Trend ini merepresentasikan bahwasanya penumpang memiliki kecenderungan untuk membayar layanan Trans Padang lebih tinggi dibandingkan kesanggupannya. Dengan demikian, diperlukan treatment khusus pada koridor Pusat Kota-Pusat Pemerintahan agar mode shift nya dapat dipertahan. Contohnya adalah melalui skema harga tiket yang disubsidi.

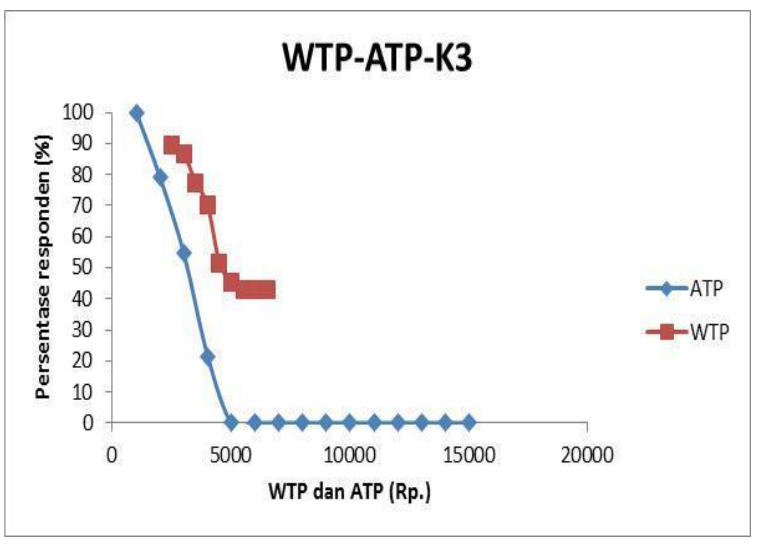

Gambar 3.1 WTP dan ATP koridor Pusat KotaPusat Pemerintahan

\section{Geometri Jaringan Jalan}

Berdasarkan data geometri jaringan jalan diperoleh hasil bahwa mobilisasi angkutan umum Trans Padang baik menggunakan Bus Besar maupun Bus Sedang secara umum tidak begitu mengalami kendala akses, namun ada 1 (satu) ruas jalan memiliki kendala yakni ruas jalan berok dengan lebar jalan 4 meter. Dengan lebar jalan 4 meter akan menyulitkan Bus Besar untuk melintasi ruas tersebut, sehingga disarankan pada lintasan ini mengoperasikan dengan menggunakan Bus Sedang.

Perencanaan Halte Koridor Pusat Kota Pusat Pemerintahan 
Pembangunan halte perlu dilengkapi sarana dan prasarana yang memadai, serta lokasi yang sesuai dengan tata ruang lingkungan. Pengaturan halte Trans Padang perlu disesuaikan dengan kebutuhan. Dalam penentuan lokasi halte trans padang terdapat beberapa kriteria yang digunakan diantaranya:

a. Penentuan lokasi didasarkan Pada

\section{Perencanaan Kota dan Persyaratan}

Penentuan lokasi halte dilakukan dengan memperhatikan rencana kebutuhan lokasi simpul jaringan aktivitas penumpang dan jalur kendaraan umum, serta perlu diperhatikan pula: Rencana umum tata ruang, kepadatan lalu lintas dan kapasitas jalan disekitar halte, keterpaduan antar moda transportasi, kondisi geografi lokasi halte, kelestarian lingkungan.

Selain itu sebaran lokasi halte harus memperhatikan berbagai aspek yang berkaitan dengan tuntutan umum (Suwardjoko P. Warpani, 2002)yaitu : Pusat keramaian yang ada, misalnya pasar, pertokoan, obyek wisata dan lain-lain; Pusat kegiatan, misalnya kantor, sekolahan dan lain-lain; Kemudahan perpindahan moda, misalnya persimpangan jalan
Melihat persyaratan umum dan pedoman praktis penentuan lokasi halte angkutan umum, maka perlu diperhatikan kondisi lapangan : Ada tidaknya trotoar, tersedianya lahan untuk membuat halte, tingkat pelayanan jalan, kecukupan lebar jalan, tingkat permintaan penumpang yang menentukan perlu tidaknya lindungan.

b. Penentuan lokasi didasarkan Pada Asal dan Tujuan Penumpang.

Untuk memperoleh lokasi halte yang sesuai dengan asal dan tujuan penumpang, perlu diketahui jumlah penumpang dari asal dan tujuannya serta kebiasaan lokasi menunggu. Jumlah, asal, tujuan penumpang dan lintasan rute kendaraan umum dapat menjadi landasan untuk memperoleh alternatif lokasi halte yang mudah dicapai, aman dan sesuai dengan kebutuhan penumpang maupun kendaraan umum sendiri.

Dengan memperhatikan aspek kondisi tata gunalahan, berikut ini penentuan jarak antara halte, dapat dilihat pada Tabel.

Tabel 3.4 Penentuan Jarak Antar Halte

\begin{tabular}{|l|l|l|l|}
\hline Zona & \multicolumn{1}{|c|}{$\begin{array}{c}\text { Tata Guna } \\
\text { Lahan }\end{array}$} & \multicolumn{1}{|c|}{ Lokasi } & \multicolumn{1}{c|}{$\begin{array}{c}\text { Jarak } \\
\text { Tempat Henti }\end{array}$} \\
\hline $\mathbf{1}$ & $\begin{array}{l}\text { Pusat kegiatan sangat padat : } \\
\text { Pasar, pertokoan }\end{array}$ & CBD, Kota & $200-300^{*}$ \\
$\mathbf{2}$ & Padat : perkantoran, sekolah, jasa & Kota & $300-400$ \\
$\mathbf{3}$ & Permukiman & Kota & $300-400$ \\
$\mathbf{4}$ & Campuran padat : sekolah, jasa & Pinggiran & $300-500$ \\
$\mathbf{5}$ & Campuran jarang :perumahan, & Pinggiran & $500-1000$ \\
& ladang, sawah, tanah kosong & & \\
\hline
\end{tabular}

Ket : $\left.{ }^{*}\right)=$ jarak $200 \mathrm{~m}$ dipakai bila sangat diperlukan saja, sedangkan jarak umumnya $300 \mathrm{~m}$. (Sumber : Departemen Perhubungan 1996)

Pada koridor Pusat Kota Air Pacah dengan lintasan RTH Imam Bonjol - Pusat Pemerintahan terdapat 39 titik pemberhentian (halte) dengan 2 halte ukuran besar yaitu halte utama yang berada di RTH Imam Bonjol yang merupakan center point dan halte Hang Tuah I (Sumber Teknik), diikuti tiga halte ukuran sedang serta 34 halte ukuran kecil. Untuk lintasan Pusat 
Pemerintahan - RTH Imam Bonjol terdapat 39 titik halte yang terdiri dari satu halte ukuran besar yaitu di RTH Imam Bonjol yang berfungsi sebagai center poin, empat halte ukuran sedang dan 34 halte ukuran kecil. Jarak antar halte bervariasi antara $250 \mathrm{~m}$ sampai 700 meter.

Dalam menentukan titik lokasi halte pada masing masing koridor ditemukan beberapa kendala yang perlu disikapi agar penempatan halte tetap bisa pada lokasi, diantaranya ketersediaan lahan yang relative sempit, adanya Pohon pelindung dan aktivitas pedagang di bahu jalan.

\section{Kesimpulan}

Dari penelitian yang telah dilakukan dapat ditarik kesimpulan :

1. Koridor pengembangan lintasan Trans Padang Pusat kota - Pusat Pemerintahan adalah sebangai berikut:

Pergi : Imam Bonjol - Karya - Gereja Diponegoro - Hangtuah - Samudera - S. Parman - Khatib Sulaiman - Jhon Anwar Gadjah Mada - Siteba - Simp. Balai Baru Sungai Sapih - Aie Pacah

Pulang :Aie Pacah - Sungai Sapih - Simp. Balai Baru - Siteba - Gadjah Mada - Jhoni Anwar - S. Parman - Juanda - Veteran Damar - Pemuda - Diponegoro - Gereja Pondok - M. Thamrin - Imam Bonjol Hasanuddin - Bagindo Aziz Chan - M. Yamin - Imam Bonjol

2. Potensi potensial demand penumpang trans Padang koridor Pusat Kota-Pusat Pemerintahan dari seluruh moda adalah 24.783 penumpang

3. Jumlah halte yang dibutuhkan Trans Padang untuk koridor Pusat Kota-Pusat Pemerintahan adalah 39 halte untuk arah pergi dan 39 halte untuk arah pulang dengan panjang trayek $22,94 \mathrm{~km}$

4. Untuk penempatan halte bus disesuaikan dengan tata guna lahan dan analisis geometrik jalan.

5. Berdasarkan analisis tata guna lahan maka bus yang dianjurkan untuk koridor ini adalah bus ukuran sedang.

\section{DAFTAR PUSTAKA}

Anonim, 1996, Pedoman Teknis Penyelenggaraan Angkutan Penumpang Umum di Wilayah Perkotanan Dalam Trayek Tetap dan Teratur. Direktorat Jendral Perhubungan Darat, Jakarta

Direktorat Jenderal Perhubungan Darat. 1996. Menuju Tertib Lalu Lintas dan Angkutan Jalan. Departemen Perhubungan Republik Indonesia.

Hook, Walter B. 2007. BRT Planning Guide.

Salim, Abbas. 1993. Manajemen Transportasi. PT. Raja Grafindo Persada. Jakarta.

Sutomo, Heru and Joisangadji, Syamsulbahry. 2002. Perencanaan strategik dalam prospek penyelenggaraan transportasi berkelanjutan di kota Yogyakarta. Thesis. Yogyakarta.

Warpani, Suwardjoko P.2002. Pengelolaan Lalu Lintas Dan Angkutan Jalan. Penerbit ITB edition, in Indonesian. 